\section{Letter from the Founding Facilitator} Richard J. Barohn, MD

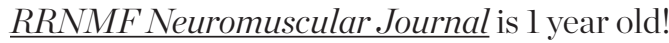

Publication of the written word is a critical communication vehicle. To have access to venues where this can be done easily is important. Once published, the message can be accessed online, shared, and cited. It is necessary to have a publication vehicle that provides a digital journal structure format, that can be registered with the Library of Congress, and that is searchable through web search tools and scholarly databases. Here are the essential steps to this process:

1. Have an idea for a journal

2. Have access to an online journal software system

3. Have assistance in developing and launching the project

4. Have interested colleagues who share the vision of such a venue and have articles to submit

5. Have students interested in being part of the production process

6. Have colleagues interested in helping to be facilitators (reviewers)

As we honor our one-year anniversary, the RRNMF Neuromuscular Journal is now truly a real academic publication. It is not PubMed indexed yet, but we are getting closer. We have published 5 issues in volume 1 in 2020 and this is the second issue in volume 2 for the year 2021. There are several steps to get started with publishing a new journal. One of the first steps is to get an International Standard Serial Number (ISSN) for the journal from the Library of Congress's ISSN site. The ISSN is a unique number that belongs to each journal. RRNMF journal's ISSN is $\mathbf{2 6 9 2 -}$ 3092 and is the key to getting other services that help make the article visible to web search engines. It is easy to apply for an ISSN and free, but you need to publish the first issue before you request it. Once we had the ISSN, the University of Kansas Libraries' Digital Publishing Services group worked with a company called Crossref to get us a Digital Object Identifier (DOI) link (all starting with https://doi. org/17161/rrnmf) that we could add to each article page. The KU Libraries pay a small fee for registering DOIs with Crossref. DOIs are great because they give each article a permanent link that will never change. Finally, the RRNMF Neuromuscular Journal is searchable on Google Scholar and our publications go into the calculation of your Google Scholar H - Index if it is cited.

How is this done at no cost to us? The University of Kansas Libraries in their wisdom established a publishing program to support open access publications edited by faculty from the University of Kansas. They installed the software for an online digital publishing platform called Open Journal Systems (OJS), which was originally developed through a Mellon grant. There are several of these available commercially, with OJS being one of the frequently used models because it is free, open source, and has an active user/developer community that is passionate about making research openly available to the world. The Libraries' digital publishing office now has over 42 journals published by KU faculty - only 2 are medical: the RRNMF Neuromuscular Journal and the Kansas Journal of Medicine. There is a staff that is essential to help faculty learn about the process and access the software program. I, like all faculty, was willing to do this on my own time; I found neurology colleagues who were willing to help; and I found two amazing medical students who were willing to help me as well. When I launched the journal prior to having the help of the medical students, I struggled. Their energy and youthful computer capabilities got us over the hump to sustainability. I currently put about several hours a week into this project, after typical work hours.

The other obvious factor to get such a project to happen is that I and my other neurology colleagues have actual real jobs that we get paid for and that we do not need income from publishing. This type of self-publishing is a non-paid labor of love done in our spare time. I wish we could pay our authors and reviewers for their time and creative work. In an ideal situation, we would have funds to do so, perhaps industry support. As for now this does not exist. In my opinion it is problematic that authors and editorial board members and reviewers do not get compensated for their time. And in our modern open access format authors often must PAY the journal to be published, often at exorbitant costs. Clearly there is a lot of profit to be made in the publishing houses. These publishers historically charged not only individuals for their subscription fees, but charged academic libraries enormous fees for publishing their catalogue of journals. As these costs rose and libraries had limited budgets, the next step was to pass this cost on to the authors. And the authors are paying these high fees because they need publications for promotion and academic advancement. This coincided historically with the push for "open access" so that research results are quickly and widely disseminated to the academic readership and public especially when the author used federal research funds to finance the research described in the publications.

So, we have circumvented this cycle through establishing our own academic publishing project. This is free of predatory financial motivated publishers, and it is free of elitist establishment editorial boards and "gotcha" reviewers. We are indeed Free at Last!

Another component of this freedom is for the author(s) to own their copyrights in the research that they publish and not the publisher. For this to happen, the journal has an agreement with each author that specifies that copyright is held by the author(s). This information is put in the copyright notice section of the journal. Our statement says: 
"Copyright in the articles and supplementary materials are held by the author(s), unless otherwise noted. All articles in the RRNMF Neuromuscular Journal are licensed under a Creative Commons Attribution-NonCommercialNoDerivatives 4.0 International License. "This means that the author(s) are the owner(s) of the article and any supplementary material unless it has prior copyrighted components. RRNMF Neuromuscular Journal does not own the papers. The Creative Commons license tells readers how they can use the research without asking for permission from the author. Authors that publish in the journal agree to apply that license to their research when they publish in the journal. The Creative Commons website has more information about how Creative Commons licenses work, as well as information about the Creative Commons Attribution-NonCommercial-NoDerivatives 4.0 International (CC BY-NC-ND 4.0) license used by our authors.

If you want to publish a case or series or your research results, or video/photographs, or a prior grant proposal, or simply an idea, then this is the journal for you.

We have put a number of unique features in this journal and we have changed journal terminology. The editorial board members and reviewers are now called facilitators as the goal is to help the author(s) get their paper published. We are not hampered by the length of an issue since we are digital, only by the time commitments of our technical partners in the digital publishing office and our facilitators. In general, our goal is to provide peer review for cases and research articles and reviews and give positive feedback so authors can improve their article. We would like to publish most submitted articles if they are sound and well written and make a good point. We do not have a goal to have a set rejection rate. We do not reject submissions if they are reasonable but we do ask authors to address the reviewer's suggestions and modify their manuscripts based on the comments.

This allows our authors additional freedoms. If their article has been rejected by a traditional journal they can come to this friendly journal. If they have a junior faculty or student or resident or fellow who is just getting started publishing, they can come to this journal. If they do not have funds to publish in an open access journal that charges authors, they can come to this journal.

Other new terminology includes "what's on your mind" instead of editorials or letters to the editor; "clinic stuff" instead of case reports; "new stuff "instead of case series and other new research; "looking back/ looking forward stuff" for reviews; "visual stuff" for photographs and videos; "meeting stuff” for abstracts and summaries of meetings; and finally, the most unique feature is "proposed stuff" where you can publish a prior grant submission that was either accepted or rejected along with the peer reviewers' comments.... the ultimate in peer review. We spend countless hours preparing and submitting grants; most are rejected. Traditionally it ends there with no academic output. But now you can publish your prior grants, with a paragraph introducing why you and your team wrote it; where it was submitted to; and if it was funded or not, and what the outcome was. I hope more of our readers and writers take advantage of this important and unique feature.

Moving forward we would like to increase our readership and also our reviewers. Anyone who registers to receive the journal can indicate if they want to be contacted as a reviewer and what their area of expertise is. We would like to find more female reviewers and reviewers that are from minority groups to get them more engaged in this process. I recently put a call out to get more reviewers in these categories involved and it has been successful. And of course, we want more articles submitted!

Also, moving forward we probably will apply to get PubMed indexing. The typical process requires the journal to be publishing for at least two years and to have at least 25 peer reviewed publications. We have the publication numbers but we still have another year to go before we can submit a formal application. However, I do want all of you to keep an open mind about the necessity for PubMed. How important is it really? I realize some want their articles to be in a journal indexed in PubMed for promotion and tenure purposes. From my senior perspective, I am not sure of the value of PubMed however. What if when we apply and it was determined we are not worthy because we did not reject enough submissions? I would take that as a badge of honor. That is our goal, to facilitate authors to publish their work. And as I mentioned above, all our articles are indexed and are searchable in Google Scholar.

Clearly you do not need a formal journal to get your ideas into the internet universe. There are social media outlets; you can set up a blog site and write pieces and send them to folks who want to receive your blog. This is an excellent way to communicate and my close friend, Dr. Josh Freeman, has done this for years in his two excellent blog sites. But when I offered Josh the opportunity to publish some of his excellent blogs in this journal, he agreed. It gives him another avenue to communicate. Another option is to set up a website that does not have a journal type of academic format, such as the excellent BrainPickings.org website. Check this amazing site out. It has a wide readership and is a place where arts and science ideas can intersect.

I have one more big idea for this type of venue and that is to create a general arts and science journal that would be a place for any artist or scientist to publish their work. I particularly would like authors to submit work that describes an intersection of art and science. I am tentatively am calling this the Midwest Journal of Arts and Science. If anyone is interested in participating or if you have Arts and Science colleagues who might want to be involved, please have them contact me. And in the meantime, before we launch another journal, I am soliciting various non-medical manuscripts for publication in the RRNMF Neuromuscular 
Journal. You will be seeing poems, short stories, and even a movie screenplay in the upcoming issues! The first poem for the journal is in this anniversary issue.

Thanks for reading this long anniversary note and for supporting the journal. And THANK YOU to our digital publishing gurus at KU, Marianne Reed and Eric Bader, who are wonderful partners and team players. Recently Pam LeRow worked in that office and she and Marianne helped us get this journal off the ground. Thanks to our amazing medical students Jiji Oufattole and Breanna Tuhlei who serve as editors. Thanks to Lauren Peck, a freshman undergraduate at MIZZOU who has helped me a great deal in getting manuscripts loaded onto the journal platform. Thanks to our associate facilitators, Drs. Yeubing Li and Michael Pulley who give us more of their time than we deserve. Thanks to our founding Board of Facilitators, and thanks to our many facilitators who I have asked to review papers who are not on the board. I will be inviting more of you to help as facilitators, and if you enjoy being part of the project, we can put you on the Board of Facilitators Thanks to all of you readers. And most importantly thank you to all authors who have taken a gamble to send their creative material to a new type of publication.

Rick 